Barbosa, F.S.; Heize, R.S.S.; Carmo, A.J.R.R.S. Planejamento logístico de restaurantes: um estudo de caso dos restaurantes de São Borja (RS). Revista Brasileira de Ecoturismo, São Paulo, v.6, n.5, nov-2013/jan-2014, pp.926-941.

\title{
Planejamento logístico de restaurantes: um estudo de caso dos restaurantes de São Borja (RS)
}

\section{Logistics planning in restaurants: a case study on three restaurants in São Borja (RS, Brazil)}

\section{Fabrício Silva Barbosa, Rafael Silvestre Serpa Heize, Annibal José Roris Rodriguez Scavarda do Carmo}

\section{RESUMO}

A expansão do setor de serviços no Brasil tem feito com que alguns municípios tenham buscado na atividade turística, uma alternativa rentável para alavancar a economia local. Esta pesquisa teve por objetivo principal investigar o processo logístico dos principais restaurantes da cidade de São Borja/RS, tomando como base a Cadeia de Valor de Porter (1999). Este estudo de caráter qualitativo teve como método um estudo de caso, e para a coleta de dados, utilizou-se um questionário semiestruturado que subsidiou as entrevistas, bem como observação dos pesquisadores. $O$ resultado da investigação aponta para uma evolução nos processos logísticos nos empreendimentos voltados para o setor de alimentos e bebidas, contudo, alguns novos processos necessitam ser implementados para uma melhoria da prestação dos serviços oferecidos.

PALAVRAS-CHAVE: : Logística; Restaurantes; Cadeia de valor; São Borja.

\begin{abstract}
The expansion of the services sector in Brazil has caused some municipalities to look to tourism activity as a viable alternative for leveraging the local economy. But for this activity to be developed in a way that meets the objectives, there is a need for companies in the region to be prepared for this new reality. The main objective of this study was to investigate the logistics process of the main restaurants in the town of São Borja/RS, based on Porter's value Chain (1999). This method used in this qualitative study was a case study. For the data collection, a semi-structured questionnaire was used that supported the interviews, as well as observation by the researchers. The results of the investigation point to an evolution in the logistics processes in companies in the food and drink sector. However, some new processes need to be implemented in order to improve the services offered.
\end{abstract}

KEY-WORDS: Logistics; Restaurants; Value Chain; São Borja.

Página 926 Revista Brasileira de Ecoturismo, São Paulo, v.6, n.5, nov 20I3-jan 20I4, pp.926-94I. Sociedade Brasileira de Ecoturismo. Rua Dona Ana, 138, Vila Mariana, São Paulo, SP - Brasil. E-mail: rbecotur@sbecotur.org.br; Tel. (55-II) 99196-7685 


\section{Introdução}

Atualmente os serviços possuem papel de destaque na atividade econômica de qualquer sociedade. Serviços de infraestrutura são primordiais para a construção do elo essencial entre todos os setores da economia, inclusive o cliente final. Em economias complexas e diversificadas, tanto os serviços comerciais quanto os de infraestrutura atuam como intermediários e também como canais de distribuição para o consumidor final. (FITZSIMMONS; FITZSIMMONS, 2005). Corroboram este pensamento Corrêa e Caon (2002) e Magnano e Cheveste (2011) quando descrevem que o setor de serviços ganha cada vez mais importância no mundo, sendo fundamental pela fomentação trabalho e geração de riqueza em vários países, o que tem possibilitado um aumento considerável do PIB dos países que tem investido no setor.

Neste contexto, percebe-se que o setor de serviços é imprescindível para o desenvolvimento sócio-econômico de uma localidade, através da geração de trabalho e renda. Ocorrem por fatores como o aumento da renda da população, entrada de classes emergentes na economia e novas tendências de consumo. Diante destes pontos, nota-se uma perspectiva otimista para crescimento deste segmento no país.

Com o crescimento do país e principalmente da economia local, O PIB do município de São Borja cresceu em 17,4\% no período de 2008/2009 (ZERO HO$R A, 2011)$. Pode-se citar que este aumento se deu em grande parte pelo setor terciário, o segmento citado corresponde a $54,3 \%$ do Valor Adicionado Bruto da cidade (FEE, 2012). Percebe-se que o propulsor do aumento da economia local foi a implantação das instituições de ensino federais, Instituto Federal Farroupilha e Universidade Federal do Pampa, o que promoveu um "boom" no segmento de serviços, principalmente nos setores de infraestrutura, imobiliário e de alimentos e bebidas.

A cidade de São Borja derivou-se da redução de São Francisco de Borja, fundada em 1682 pelo jesuíta espanhol Padre Francisco Garcia, sendo este o primeiro dos sete povos das missões. O município é conhecido, também, como "Terra dos presidentes", por ser a terra natal de grandes estadistas, os expresidenciáveis Getúlio Vargas e João Goulart (PINTO, 2010). São Borja está localizada na região da fronteira-oeste do Rio Grande do Sul, onde faz fronteira com a cidade argentina de Santo Tomé, possui população total de 61.662 habitantes, (IBGE, 2012). Destacam-se os atrativos culturais, turísticos do agronegócio e mais recentemente a transformação da cidade em um grande polo educacional.

A presente investigação tem como objetivo principal investigar o processo logístico das empresas do segmento de alimentos e bebidas do município de São Borja/RS. Para que o objetivo fosse alcançado, utilizaram-se como objeto de estudo os três principais restaurantes da cidade. Esta pesquisa de caráter qualitativo teve como método a estruturação de um estudo de caso, onde foi utilizado o modelo da cadeia de valor em serviços criada por Porter (1999). 
A coleta de dados foi feita através de entrevistas realizadas com os gerentes e proprietários dos estabelecimentos. O processo de entrevistas foi subsidiado com aplicação de questionários semiestruturados. Os autores também utilizaram informações obtidas através de suas experiências como clientes dos estabelecimentos estudados. Os resultados da pesquisa apontam para a necessidade de implementação de novos processos, o que resultará em um avanço da prestação de serviços no setor local de alimentos e bebidas.

\section{Fundamentação teórica}

\section{Logística}

$\mathrm{Na}$ Antiguidade, os produtos desejados eram produzidos onde as pessoas gostariam de consumi-los. Todos os produtos, incluindo alimentos, estavam amplamente dispersos e disponíveis em abundância apenas em certos períodos do ano. Sendo assim, eles deveriam ser consumidos de imediato e nos locais onde se encontravam, ou então, deveriam ser armazenados para uso posterior. Todo este processo fazia-se necessário por não haver um sistema de transporte e distribuição organizado, bem como sistemas de armazenagem bem estruturados (BALLOU, 2001). Para Pires (2004), a logística como área de atuação e conhecimento humano existe há muito tempo, e os livros tradicionais reforçam o caráter militar que a disciplina adquiriu, o que foi de grande importância na antiguidade. Ressalta-se que, há não muito tempo, o departamento logístico desempenhava uma função secundária dentro das empresas. Mas o tempo passou, trazendo mudanças e novas formas de se trabalhar com a logística. Estas mudanças e o surgimento de uma nova forma de trabalho foram impulsionados por uma série de acontecimentos ocorridos nas últimas décadas. Segundo Christopher (1997, p.2), "os princípios de gerenciamento logístico levaram uns setenta anos ou mais para serem claramente definidos".

A logística foi fundamental na história da humanidade e continua até hoje para as organizações, porém, ganhou maior destaque dentro das empresas após a Segunda Guerra Mundial. A partir dela, tem crescido de forma contínua, não deixando de lado a sua ligação direta com a logística militar. Durante a referida guerra (1939-1945), a logística foi utilizada de forma global e estabeleceu-se uma ligação direta integrada a estratégias e táticas que serviam de apoio às atividades militares (DA SILVA; MUSETTI, 2003).

O conceito de logística também acompanhou a sua evolução. Hoje a logística apresenta uma interface fundamental junto à produção e ao marketing, tornando-se instrumento de extrema e fundamental importância dentro dos processos. A partir da segunda fase, apresentada no quadro abaixo, é possível claramente observar que a logística adquire um caráter essencialmente estratégico, funcionando como uma grande ferramenta dentro das organizações (WOOD JÚNIOR, 2004). 
A Tabela 1, criada por Wood Júnior, demonstra as diversas fases ligadas à evolução do conceito de Logística:

Tabela 1: Evolução do conceito de logística.

Table 1: Evolution of the concept of logistics.

\begin{tabular}{|c|c|c|c|c|c|}
\hline Fases & $\begin{array}{l}\text { Fase } \\
\text { zero }\end{array}$ & $\begin{array}{l}\text { Primeira } \\
\text { fase }\end{array}$ & $\begin{array}{l}\text { Segunda } \\
\text { fase }\end{array}$ & $\begin{array}{l}\text { Terceira } \\
\text { fase }\end{array}$ & $\begin{array}{l}\text { Quarta } \\
\text { fase }\end{array}$ \\
\hline $\begin{array}{l}\text { Perspectiva } \\
\text { dominante }\end{array}$ & $\begin{array}{l}\text { Administração } \\
\text { de materiais }\end{array}$ & $\begin{array}{c}\begin{array}{c}\text { Administração } \\
\text { de materiais } \\
+ \\
\text { Distribuição }\end{array} \\
\end{array}$ & $\begin{array}{l}\text { Logística } \\
\text { integrada }\end{array}$ & $\begin{array}{l}\text { Supply chain } \\
\text { management }\end{array}$ & $\begin{array}{c}\text { Supply chain } \\
\text { management } \\
+ \\
\text { Efficient } \\
\text { consumer } \\
\text { response }\end{array}$ \\
\hline Focos & $\begin{array}{l}\text {-Gestão de } \\
\text { estoques } \\
\text {-Gestão de } \\
\text { compras } \\
\text {-Movimentação } \\
\text { de materiais }\end{array}$ & $\begin{array}{l}\text {-Otimização do } \\
\text { sistema de } \\
\text { transporte }\end{array}$ & $\begin{array}{c}\text {-visão sistêmica } \\
\text { da empresa } \\
\text {-Integração por } \\
\text { meio de sistema } \\
\text { de informações }\end{array}$ & $\begin{array}{c}\text {-visão sistêmica } \\
\text { da empresa } \\
\text { incluindo } \\
\text { fornecedores e } \\
\text { canais de } \\
\text { distribuição }\end{array}$ & $\begin{array}{l}\text {-Amplo uso de } \\
\text { alianças } \\
\text { estratégicas, } \\
\text { co-makership, } \\
\text { subcontratação } \\
\text { e canais } \\
\text { alternativos } \\
\text { de distribuição }\end{array}$ \\
\hline
\end{tabular}

Fonte: Wood Júnior (2004, p.214). Source: Wood Júnior (2004, p.214).

Na definição proposta pela Council of Logistics Management (CLM), a logística seria uma parte integrante daquilo que comumente se entende por cadeia de suprimento, demonstrando que é preciso a gestão eficiente de fluxos de bens, serviços e informações, desde a obtenção de insumos até sua distribuição. Nas palavras de Figueiredo, Fleury e Wanke (2003, p. 28), logística é:

O processo de planejar, implementar e controlar eficientemente, ao custo correto, o fluxo de armazenagem de matérias-primas, estoque durante a produção e produtos acabados, e as informações relativas a estas atividades,desde o ponto de origem até o ponto de consumo, com o propósito de atender aos requisitos do cliente.

Através da citação acima, leva-se a crer que o processo logístico é capaz de desenvolver vantagem competitiva para as organizações, uma vez que a grande concorrência, em conjunto com altos custos das empresas, planejar todas as atividades que fazem parte do referido processo são fundamentais no objetivo de proporcionar o melhor atendimento ao consumidor, à medida que, garantindo a satisfação do mesmo, permitem a sua fidelização. Bowersox e Closs (2001) confirmam que organizações que usufruem de competência logística, obtêm vantagem competitiva e propiciam aos seus clientes um serviço com qualidade superior (excelência). 


\section{Cadeia de suprimentos e rede de valor}

Com a ampliação da concepção do conceito de logística, faz-se necessário o estudo da cadeia integrada, criada entre a interação de fornecedores e clientes que deve ser gerida como uma entidade única. Em um primeiro momento, dizia-se em acabar com as barreiras entre as empresas, tendo em vista a promoção e integração dos processos de cada uma delas. Esta ideia é entendida como cadeia de suprimentos, segundo os ensinamentos de Christopher (1997). A gestão da rede de suprimentos é uma metodologia desenvolvida para alinhar de maneira eficiente todas as atividades de produção de maneira sincronizada, com o intuito de reduzir custos, minimizar ciclos, maximizar o valor percebido pelo cliente final em busca de resultados superiores por meio da redução das barreiras no ambiente interno da organização ou entre organizações.

No entendimento de Bowersox, Closs e Cooper (2006), a cadeia de suprimentos oferece uma estrutura para negócios e seus fornecedores, que trabalham em conjunto para que as mercadorias, serviços e informações cheguem até os consumidores da forma mais rápida e eficiente, ocasionando a satisfação destes. Ainda de acordo com Bowersox, Closs e Cooper (2006), a gestão da cadeia de suprimentos compreende empresas que colaboram na busca por um posicionamento estratégico que possa garantir a melhoria de seus serviços.

Outrossim, a logística torna-se uma ferramenta de extrema importância para a criação de vantagens competitivas no mercado de serviços, no qual está inserido o setor de serviços. Para ratificar este pensamento, Porter (1985, p.89) afirma que:

A vantagem competitiva não pode ser compreendida olhando-se para uma empresa como um todo. Ela deriva das muitas atividades discretas que desempenha, projetando, produzindo, entregando e apoiando o seu produto. Cada uma dessas atividades pode contribuir para a posição de custo relativo da empresa e criar a base para a diferenciação. A cadeia de valor desdobra a empresa em suas atividades estrategicamente relevantes, para compreender o comportamento dos custos e as fontes de diferenciação existente ou potenciais. Uma empresa ganha vantagem competitiva executando estas atividades estrategicamente importantes de maneira mais barata, ou melhor, que seus concorrentes.

Por isso é importante desenvolver a análise da cadeia de valor de Porter (1999), porque é considerado o mais completo e adequado ferramental estratégico para ser utilizado nas empresas prestadoras de serviços. As principais variáveis analisadas para esta constatação foram: determinação do valor agregado aos serviços, vantagem competitiva e os principais custos.

A Figura 1 demonstra como foi estruturado o modelo da cadeia utilizada por Porter (1999). 


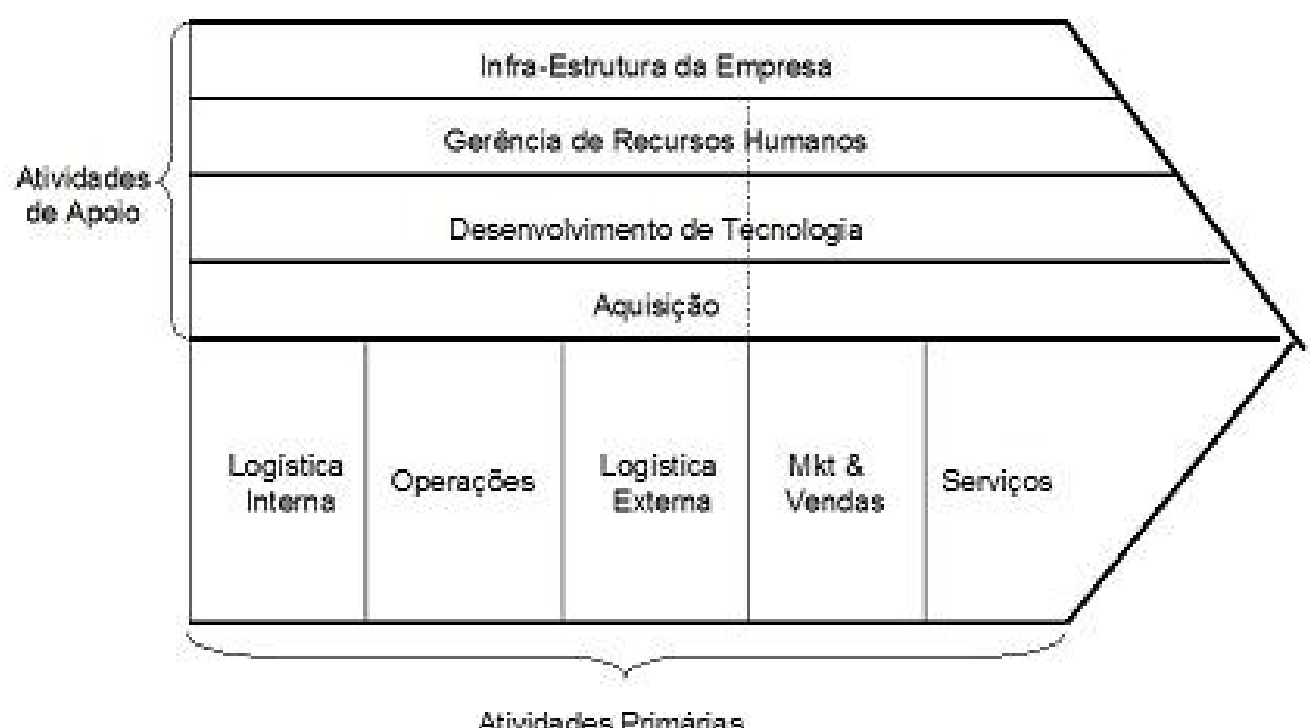

Figura 1: Cadeia de valores genérica criada por Porter.

Figure 1: Generic Value Chain created by Porter

Fonte: Porter (1999, p.35).

Source: Porter (1999, p.35).

A cadeia proposta por Porter (1999) deve ser adaptada caso a caso para cada empresa, e possibilita a elas agregar valor no mercado em que estão inseridas por meio das suas atividades, divididas em atividades principais (primárias) e de apoio. Atividades principais compreendem aquelas voltadas diretamente ao sistema produtivo. Já as atividades de apoio dizem respeito às que proporcionam suporte a todas as demais atividades, permeando toda a organização, possibilitando a efetivação das atividades primárias (SILVA et. al., 2007).

As atividades ligadas à cadeia de valor estão vinculadas umas às outras e, por completarem-se, é quase impossível separá-las, principalmente em empresas do segmento de prestação de serviços, nas quais as atividades são integradas, quase nunca sendo verificada a independência entre elas (PORTER, 1999; WOOD JÚNIOR, 2004; GAZERRA, 2005).

\section{Procedimentos metodológicos}

Esta investigação tem por objetivo analisar o processo logístico dos principais restaurantes da cidade de São Borja/ RS. A abordagem será qualitativa, exploratória, com corte transversal, e o método a ser utilizado é o estudo de caso. Segundo Triviños (1987), na pesquisa qualitativa, o ambiente natural é a fonte direta dos dados, e o pesquisador é o instrumento-chave. Richardson (1999) afirma que neste tipo de pesquisa se procura uma compreensão detalhada dos significados e características situacionais apresentadas pelo entrevistado. Para Flick (2004), é importante ressaltar que as ideias centrais que norteiam a pesquisa qualitativa são diferentes das encontradas nas pesquisas quantitativas. Alguns aspectos devem ser considerados, tais como: a habilidade do pesquisador na escolha de métodos e teorias que se adaptem ao objeto de estudo, a identificação e verificação das diferentes perspectivas, o reconhecimento por parte do pesquisador de que 
sua pesquisa faz parte de um processo de produção de conhecimentos e a diversificação na aplicação de técnicas e métodos. O caráter exploratório permite a familiarização do problema com o intuito de torná-lo explícito, sendo muito comum, neste tipo de pesquisa, a utilização de dados fontes secundárias (BABBIE, 1998; DENCKER, 1998). Argumenta Dencker (1998) que a pesquisa exploratória permite a flexibilidade do planejamento, envolve em grande parte levantamento bibliográfico, entrevistas com pessoas experientes, e quase sempre se apresenta como estudo de caso. Para Yin (2005, p 32), estudo de caso é uma investigação empírica sobre "[...] um fenômeno dentro do seu contexto de vida real, especialmente quando os limites entre o fenômeno e o contexto não estão claramente definidos". CompartiIha este pensamento Eisenhardt (1989), acrescentando que o estudo de caso tornará viável a elucidação sobre temáticas que ainda não tiveram propostas de estudos mais aprofundadas.

Quanto ao tempo em que os dados foram coletados, a pesquisa apresenta corte transversal (cross-sectional). Para Sampieri et al. (1991, p.2), o corte transversal acontece quando "a coleta de dados ocorre em um só momento, pretendendo descrever e analisar o estado de uma ou mais variáveis em um dado momento". Caso a coleta de dados ocorresse em momentos distintos, originaria o corte longitudinal.

A coleta de dados foi obtida através de entrevistas semiestruturadas com os gerentes e proprietários dos restaurantes. A pesquisa bibliográfica também foi utilizada como instrumento de coleta de dados. De acordo com Marconi e Lakatos (2005), a utilização da pesquisa bibliográfica ocorre no momento em que o pesquisador tem a percepção da necessidade de levantamento de dados sobre assuntos específicos.

\section{Resultados da pesquisa}

\section{Caracterização dos empreendimentos pesquisados}

Os empreendimentos utilizados como objeto de estudo nesta investigação são restaurantes bem frequentados, altamente conceituados pela comunidade local, com características peculiares e cujos proprietários possuem uma vasta experiência no setor de alimentos e bebidas. São considerados os três maiores restaurantes da cidade. Como forma de preservar a identidade dos locais, chamaremos os restaurantes $A, B$ e $C$ respectivamente.

\section{Identificação da cadeia de valor dos empreendimentos pesquisados}

O modelo que norteou a identificação da cadeia de valor dos empreendimentos estudados foi o proposto por Porter (1999). Utilizaram-se como condutores para a apresentação dos dados coletados do objeto de estudo o constructor atividades de apoio, que está diretamente ligado às variáveis: infraestrutura, recursos humanos, administração e tecnologia da informação; e o constructor atividades primárias, relacionado às variáveis logística operacional, marketing e pós-venda (BARBOSA, 2010).

\section{Atividades de apoio}

Segundo Porter (1999), as atividades de apoio são as que sustentam as atividades primárias, fornecendo recursos para que elas exerçam suas funções dentro da cadeia de valor. 


\section{Infraestrutura}

O restaurante $A$ existe na cidade há 16 anos, possui 45 mesas e a sua capacidade de carga é para 180 clientes sentados confortavelmente. A entrevista foi realizada com a proprietária do restaurante que explanou a respeito da grande dificuldade de se trabalhar com a atual infraestrutura do restaurante. $\mathrm{Na}$ opinião da entrevistada, o atual espaço físico disponível para atendimento dos clientes não atende mais as necessidades do empreendimento. O estabelecimento cresceu mais do que as expectativas de seus gestores, contudo, existem projetos para a aquisição de um prédio próprio, uma vez que o restaurante funciona em um prédio locado. Para a entrevistada, o problema do espaço é o grande desafio a ser vencido. O restaurante A é uma empresa totalmente familiar, não possui apoio de uma assessoria jurídica e a gestão do empreendimento é totalmente realizada através dos conhecimentos empíricos adquiridos pelos seus gestores durante o tempo de existência da empresa. O planejamento financeiro é totalmente organizado pelos proprietários, que não recorrem às instituições bancárias para realizar projetos dentro da empresa. A entrevistada informou ainda que quase todas as ações do restaurante referentes aos processos que são realizados estão centralizadas em seus gestores. A respondente informou ainda que considera esta centralização uma falha grave, porém, há uma grande dificuldade de se contratar mão de obra qualificada para desempenhar atividades em níveis gerenciais, motivo este que cada vez mais aumenta a centralização das atividades em poucas pessoas. A empresa não desenvolve nenhum tipo de programas relacionados à qualidade da prestação de serviços.

A segunda entrevista foi realizada com a proprietária do restaurante B. Na oportunidade a respondente explicou que a estrutura atual do restaurante atende todas as necessidades do empreendimento. O restaurante $B$ existe na cidade há 20 anos, possui 80 mesas e atende cerca de 150 pessoas diariamente. Por ser uma empresa familiar, os proprietários fazem todo o planejamento de gestão da empresa. A entrevistada explicou ainda que um dos grandes desafios da empresa foi a grande reforma realizada no restaurante há dois anos. Reforma esta que foi executada com recursos oriundos de instituições bancárias, mas que a empresa já conseguiu pagar quase que em sua totalidade. $A$ empresa conta com um setor contábil, e também com uma assessoria jurídica quando necessário. $O$ restaurante $B$ funciona em prédio próprio e tem na sua estrutura e qualidade da alimentação oferecida os seus principais diferenciais, segundo a entrevistada. O público alvo do restaurante compõe-se de empresários, funcionários públicos e os hóspedes do hotel localizado ao lado do restaurante. Para a proprietária do restaurante $B$, hotel e restaurante estão interligados e um colabora com o funcionamento do outro.

A terceira e última entrevista foi realizada com o gerente do restaurante $C$ que nos recebeu e colaborou com esta investigação. O restaurante $C$ existe na cidade de São Borja há 30 anos, possui 75 mesas e funciona em prédio próprio. Segundo o gerente geral do restaurante, a estrutura física atual atende as necessidades do empreendimento. $O$ respondente informou que o restaurante possui um escritório contábil que presta serviços para empresa, porém, o proprietário do restaurante é o grande responsável pela parte contábil e jurídica, uma vez que possui formação na área. Segundo o gerente do restaurante $\mathrm{C}$, o grande diferencial da empresa é os alimentos que são servidos. O restaurante não economiza na compra das matérias-primas que são utilizadas para preparação dos pratos. $O$ restaurante $C$ trabalha com metas, cujo alcance acontece quando o gestor do empreendimento consegue diminuir os custos, conforme explicado pelo gerente. Atual- 
mente a empresa está implantando um programa de qualidade junto aos seus colaboradores, que tem como foco o atendimento e relacionamento com o cliente.

\section{Recursos humanos}

Com relação aos recursos humanos, o restaurante $A$ conta atualmente com uma equipe de 17 colaboradores devidamente registrados, incluindo os familiares que atuam no empreendimento. No total, cerca de 20 pessoas divididas entre cozinheiros, garçons, maitres, gerentes e outros que trabalham diretamente no restaurante. $\mathrm{Na}$ opinião da entrevistada, uma das maiores dificuldades para a contratação de pessoas é a falta de profissionais qualificados na cidade. Muitas vezes a administração do restaurante opta em contratar pessoas sem experiência, porém, com vontade para aprender, pois desta forma elas podem ser moldadas de acordo com o perfil da empresa. Uma curiosidade relatada pela entrevistada refere-se a um critério peculiar utilizado por ela, para fazer contratação de cozinheiras e ajudantes de cozinha. Ela relatou que durante a entrevista observa as unhas da candidata. E em hipótese alguma contrata pessoas com unhas grandes ou compridas. Mais uma vez a falta de mão de obra qualificada foi apontada como um dos grandes problemas do setor hoteleiro da cidade de São Borja.

A proprietária do restaurante $B$ informou que a mentalidade das pessoas ainda é muito provinciana, não estão dispostas a mudanças, motivos estes pelos quais não são disponibilizados cursos de capacitação ou programas de qualificação. Segundo a respondente as pessoas possuem dificuldades para assimilar as novas tendências do mercado. $O$ restaurante $B$ não conta com nutricionista, e trabalha e funciona atualmente com cerca de vinte e três colaboradores. A respondente informou ainda que costuma aceitar indicações no processo de seleção dos colaboradores e proporcionar upgrades para aqueles que mais se destacam em suas funções.

Já o restaurante $\mathrm{C}$ conta atualmente com dezoito colaboradores em seu quadro funcional, todos devidamente registrados. $O$ processo para contratação de funcionários ocorre via análise de currículo e da verificação das habilidades do candidato. A gerência do hotel não aceita indicações, mas procura checar todas as informações citadas pelo candidato no ato da entrevista. Na opinião do gerente do restaurante este é o método mais eficiente para contratação de colaboradores. A empresa dentro das possibilidades procura oferecer cursos de capacitação e treinamento aos seus colaboradores, além de incentivar a qualificação dos mesmos. O respondente informou ainda que todas as normas internas do estabelecimento são claras e que estão à disposição de todos os funcionários.

\section{Administração}

O processo de compras do restaurante $A$ acontece diariamente. A entrevistada explicou que o restaurante não trabalha com armazenagem de suprimentos. Na ocasião, ela ainda demonstrou o desejo de no futuro implantar um sistema que possa viabilizar a criação de um estoque no restaurante. A entrevistada citou ainda que todos os perecíveis, como frutas, legumes e verduras são comprados diariamente. As carnes são entregues pelo açougue diariamente e os únicos itens que são estocados são: camarão, cortes de frango e batata palito. As bebidas também são entregues diariamente pelos fornecedores. Com relação às compras de móveis e equipamentos, estes são comprados de acordo 
com a necessidade apresentada pelo estabelecimento.

De acordo com a proprietária do restaurante $\mathrm{B}$, o processo de compras da empresa acontece diariamente. O restaurante, ainda que possua uma boa estrutura física, não dispõe de um sistema de gerenciamento de estoques. A entrevistada considera de suma importância a implantação do sistema, porém, a forma como a empresa opera atualmente, segundo a respondente, atende as necessidades do empreendimento. Com relação à armazenagem de suprimentos, poucos produtos são estocados. As compras são realizadas diariamente de acordo com as necessidades.

No restaurante $\mathrm{C}$ o processo de compras não é muito diferenciado dos outros estabelecimentos pesquisados. As compras são realizadas diariamente e somente os produtos industrializados são estocados e mesmo assim em uma pequena quantidade. Frutas e verduras são compradas diariamente, segundo o gerente do restaurante a falta de consciência das pessoas que utilizam as matérias-primas inviabiliza a estocagem de suprimentos. Os funcionários não conseguem ter o controle necessário para se manter um estoque. As bebidas também são entregues pelo fornecedor duas vezes por semana no próprio restaurante. Com relação à aquisição de móveis e equipamentos, o entrevistado explicou que a aquisição dos mesmos só acontece em casos de extrema necessidade, pois como foi citada anteriormente, a meta do restaurante é diminuir os custos.

\section{Tecnologia da informação}

O restaurante $A$ não utiliza nenhum tipo de Sistemas de gerenciamento de informação ou sistemas que estejam relacionados à Tecnologia da Informação. A proprietária do restaurante reconhece a importância dos recursos tecnológicos nas empresas em dias atuais, explicou que existem projetos para a implantação de sistemas que facilitem os processos na empresa. Contudo, todos os processos do restaurante A acontecem manualmente. O restaurante $B$ não dispõe de nenhum tipo de sistema de gerenciamento que esteja atrelado à Tecnologia da Informação. Segundo a entrevistada a gestão do restaurante é feita através dos conhecimentos empíricos adquiridos durante os 20 anos de existência da empresa. O restaurante $C$ não conta com o apoio de recursos ligados a TI. Todos os processos do empreendimento acontecem manualmente.

\section{Atividades primárias}

\section{a) Logística operacional}

$O$ restaurante $A$ inicia suas atividades às $7 \mathrm{~h}$ todos os dias. $O$ restaurante não possui serviços de nutricionista e o cálculo da comida preparada diariamente é feito de acordo com a média de consumo diário. A entrevistada explicou ainda que o consumo é maior do dia 28 ao dia 15 de cada mês. Depois deste período o consumo diminui bastante. A entrevistada explicou que todos os alimentos ficam prontos às $11 \mathrm{~h}$, pois às $11 \mathrm{~h} 30$, já tem uma grande quantidade de pessoas esperando para almoçar. Questionada a respeito da falta de uma padronização no cálculo dos alimentos preparados, a entrevistada explicou que prefere que todos os clientes que chegam durante o horário de pico sejam bem atendidos e servidos, e os que chegarem após as $13 \mathrm{~h}$ possam se servir não das sobras, mas que fiquem sem consumir alguns pratos diferenciados preparados e consumidos no horário de grande movimento. O restaurante do hotel A serve todos os dias aproximadamente 
200 refeições nos horários de pico, podendo atender aproximadamente mais 20 refeições depois das $13 \mathrm{~h} 30 \mathrm{~min}$. Também funciona à noite, com rodízios de pizzas, tele entrega de pratos $A$ La carte e pizzas.

O restaurante $B$ inicia as suas atividades impreterivelmente às $7 \mathrm{~h}$, pois às $11 \mathrm{~h}$ já existem clientes para serem atendidos. O restaurante não possui cálculos específicos da quantidade de alimentos que serão preparados. A entrevistada explicou que a empresa trabalha com uma média do que é vendido diariamente. Caso seja verificada a possibilidade de faltar algum tipo de prato, a reposição é feita de imediato, como por exemplo, as saladas que são preparadas quase que ao mesmo tempo em que são consumidas. Esta reposição torna-se mais difícil na parte dos grelhados, de forma que os clientes que chegam após o horário de pico não costumam encontrar alguns tipos de cortes. O restaurante funciona diariamente para o almoço e à noite com rodízio de pizzas, rodízio de filés, pratos a La Carte e happy hours.

As atividades no restaurante $C$ são iniciadas às $7 \mathrm{~h} 30 \mathrm{~min}$, pois a regra é que às $11 \mathrm{~h} 30 \mathrm{~min}$ o Buffet esteja totalmente montado e o restaurante pronto para atender aos seus clientes. O restaurante não faz um cálculo específico para preparação dos pratos diariamente, os alimentos são preparados com base na média de venda diária, sendo que aos domingos esta quantidade dobra. O restaurante não possui nutricionista, e os cardápios são montados e supervisionados pela proprietária do restaurante. $O$ restaurante atende cerca de 200 pessoas diariamente para o almoço e uma média de 60 pessoas pela parte da noite com serviço de tele entrega e pratos $A$ La Carte.

\section{b) Marketing e pós-vendas}

A proprietária do restaurante A considera como grande diferencial da sua empresa 0 atendimento. Tratar as pessoas pelo nome, tomar um café e comentar as notícias da cidade são estratégias utilizadas pelos gestores do restaurante para fidelizar os seus clientes. Para a entrevistada, a propaganda "boca a boca" é a grande responsável pelo sucesso do seu restaurante. O restaurante $A$ não realiza serviço de pós-vendas. A proprietária do restaurante $B$ explicou que atualmente o restaurante do hotel se autovende pela qualidade dos serviços oferecidos e pela estrutura física que o mesmo possui. Contudo, quando existe a necessidade da utilização de divulgação da empresa recorre-se à utilização de algumas ferramentas tais como: rádio, carro de som e plotagem na frota de veículos da empresa. As principais ferramentas de comunicação e marketing utilizadas pelo restaurante $C$ são: rádio, jornais, panfletagens e a criação de promoções para suprir períodos sazonais, como por exemplo, no inverno, período em que o movimento costuma cair consideravelmente. Não são realizadas ações de pós-vendas.

\section{c) Identificação da rede de valor dos empreendimentos estudados}

A identificação da rede de valor dos empreendimentos pesquisados teve como subsídio o modelo teórico proposto por Wood Júnior (2004). O constructor rede de valor norteou este subitem da investigação que teve ainda como variáveis: fornecedor, distribuidor, atacadista e varejista. (BARBOSA, 2010). 


\section{d) Fornecedores}

O fator determinante para a escolha dos fornecedores do restaurante $A$ é o preço. Claro que fatores como atendimento e qualidade também são considerados. A entrevistada informou ainda que com base nestes critérios, ela mantém alguns fornecedores há aproximadamente 16 anos. A respondente confirmou ainda que alguns serviços do restaurante são terceirizados, dentre eles o serviço de limpeza da cozinha, que facilita o trabaIho dos colaboradores que utilizam o ambiente, os serviços de manutenção e conservação do prédio e os serviços de tele entrega. Os Constructors distribuidores, atacadistas e varejistas não se aplicam ao empreendimento pesquisado. Segundo a entrevistada, o fator qualidade determina a escolha de seus fornecedores, seguido do fator preço. $O$ fator qualidade para a respondente é o mais importante, pois ele determinará a qualidade dos alimentos que serão oferecidos aos clientes do restaurante. O restaurante $B$ não terceiriza nenhum tipo de serviço, pois todos são executados pela própria staff do restaurante. Com relação aos distribuidores, o restaurante $B$ conta o apoio dos responsáveis pelas excursões que visitam São Borja. Segundo a entrevistada, os grupos fazem reserva dos lugares que serão ocupados em dias e horários pré-determinados. Segundo a respondente a escolha do restaurante é feita pela estrutura e qualidade dos serviços, não envolvendo nenhum tipo de comissão para os responsáveis pelos grupos. O constructo varejista não se aplica ao restaurante $B$. Segundo o gerente do restaurante $C$, o principal fator levado em consideração na escolha de um fornecedor é a qualidade, pois a partir deste requisito será possível oferecer um produto que atenda as necessidades dos clientes. Outro fator considerado importante é a pontualidade dos fornecedores. E o fator preço para o respondente é o último fator a ser considerado. O restaurante $C$ preocupa-se acima de tudo com a qualidade dos produtos que estão sendo oferecidos, mesmo que isto faça com que a sua margem de lucro seja diminuída. Os constructos varejistas e distribuidores não se aplicam ao restaurante $\mathrm{C}$.

\section{Análise dos dados coletados}

\section{Análise da cadeia de valor dos empreendimentos pesquisados}

Os resultados da pesquisa apontam que a atual infraestrutura dos empreendimentos pesquisados atende às necessidades dos restaurantes pesquisados. A exceção ficaria por conta da infraestrutura do restaurante $A$, pois segundo relatos da proprietária, se houvesse a possibilidade de dispor de um espaço maior seria possível proporcionar um meIhor atendimento aos seus clientes. Para Porter (1999), o planejamento financeiro é indispensável quando da consolidação da infraestrutura de uma organização. O autor salienta que uma vez não planejado adequadamente, pode vir a comprometer todo o planejamento estratégico desenvolvido para aquela empresa. Com relação aos Recursos Humanos, todos os entrevistados foram unânimes em citar a grande dificuldade de se conseguir mão de obra qualificada para trabalhar nos restaurantes. Contudo, esta dificuldade vem sendo suprida de forma gradativa a partir da iniciativa das Instituições de Ensino localizadas na cidade, que vêm oferecendo cursos direcionados para o setor de alimentos e bebidas. Allen et al (2008) salientam que a melhor opção neste tipo de empreendimento, onde o carro chefe é a prestação de serviços, é que seja evitada a rotatividade de colaboradores uma vez que esta mudança drástica constante compromete os processos operacionais da empresa.

Os resultados da pesquisa mostram que todos os empreendimentos pesquisados 
são empresas familiares, e a gestão é feita por pessoas sem formação acadêmica, com predominância dos conhecimentos empíricos adquiridos ao longo do trabalho desenvolvido na administração das empresas. O destaque para este quesito fica por conta da administração do restaurante $\mathrm{C}$, pois, ainda que seja uma empresa familiar, possui um gerente atualizado sobre as novas tendências relacionadas ao mercado do segmento de alimentos e bebidas. Com relação à tecnologia da informaçãodos empreendimentos pesquisados, os processos disponíveis apresentam-se ainda de forma incipiente, constituindo um grande desafio a ser vencido pela gestão dos restaurantes estudados. Segundo os entrevistados, é de extrema importância que os processos ocorram de forma mais dinâmica, uma vez que todos eles atualmente acontecem de forma manual. Laudon (1999) salienta a importância da implantação de LIS (Sistemas de Informações Logísticas), pois estes sistemas colaboram no processo de dinamização das constantes atividades que estão atreladas as empresas prestadoras de serviços.

\section{Análise das atividades primárias da cadeia de valor dos empreendimentos estuda- dos}

O planejamento inicial das compras determina o funcionamento da logística operacional implementada pelos empreendimentos estudados. Os resultados da pesquisa mostraram uma falta de planejamento prévio de suprimentos a serem utilizados nas atividades dos restaurantes. É importante salientar que a logística operacional altera-se conforme o planejamento inicial de cada processo. Como o planejamento é feito diariamente e de acordo com as necessidades de cada empresa, fica inviabilizada a possibilidade de uma análise mais detalhada destas atividades. Ressalta-se que as atividades primárias estão diretamente ligadas com a obtenção, transformação e comercialização de produtos e serviços (PORTER, 1999).

Constatou-se que cada empreendimento estudado organiza uma programação diária que está atrelada ao funcionamento de suas atividades, e que esta forma de trabalho atualmente atende as ações atreladas aos processos logísticos operacionais. As operações de marketing dos restaurantes estudados ocorrem somente quando da necessidade de promover algum evento ou promoção do estabelecimento. A pesquisa mostrou que as ferramentas de marketing quase não são utilizadas pelas empresas pesquisadas. Segundo Porter (1999), a promoção indevida de produtos e serviços possui um reflexo direto na receita que a organização deixa de ganhar. Os empreendimentos atualmente se autovendem, sendo a utilização da propaganda "boca a boca" a principal ferramenta de marketing apontada pelos entrevistados. Com relação às ações de pós-venda, os entrevistados informaram que praticamente não acontecem. Existe apenas um breve contato com os clientes que tem como objetivo verificar eventuais problemas operacionais que possam ser sanados de imediato.

\section{Análise da identificação da rede de valor dos empreendimentos estudados}

Com relação aos fornecedores dos restaurantes estudados, os entrevistados apontaram diferentes critérios utilizados pelas empresas para a escolha de seus fornecedores. Os principais critérios identificados foram: preço, pontualidade e qualidade. Bowersox e Closs (2001) comentam a importância da empresa estar inserida em uma rede de valor organizada, que proporcione interação entre os participantes. O resultado deste processo é um aumento na eficiência dos processos operacionais. Atenção especial para o fator qualidade, que segundo os entrevistados é fundamental para que seja possível a presta-

Página 938 Revista Brasileira de Ecoturismo, São Paulo, v.6, n.5, nov 20।3-jan 20।4, pp.926-94I. 
ção de um serviço de qualidade aos frequentadores dos restaurantes. $O$ fator preço, muitas vezes citado pelos entrevistados, também conta muito no momento da escolha do fornecedor, contudo, não supera a relevância do quesito qualidade. Em se tratando de distribuidores, atacadistas e varejistas, verificou-se que estes itens não se aplicam aos empreendimentos pesquisados.

\section{Considerações finais}

Com base nos resultados alcançados, faz-se necessário registrar algumas contribuições verificadas no decorrer da pesquisa. A primeira está relacionada diretamente à importância do tema apresentado. Conforme dados apresentados neste trabalho, verificou -se que a logística integrada ao segmento de alimentos e bebidas, em uma cidade pequena localizada na fronteira, ainda não se consolidou como um grande tema explorado pela comunidade acadêmica, o que possibilita que novas pesquisas sejam realizadas e, talvez, novos modelos para análises de processos logísticos em restaurantes maiores ou do mesmo porte possam ser apresentados.

A segunda contribuição ocorre quando se verifica que a dinâmica de funcionamento da logística em restaurantes localizados em cidades do porte de São Borja é totalmente diferente da realidade logística de restaurantes localizados em grandes centros, o que torna necessária a utilização de logística integrada que se adapte a estas peculiaridades. Também foi verificado que o atual modelo de logística integrada utilizado pelos empreendimentos pesquisados atende as suas necessidades, contudo, mudanças nos processos fazem-se necessárias para que o serviço torne-se mais funcional.

Por fim, salienta-se a necessidade contínua em aperfeiçoar os processos logísticos no segmento de alimentos e bebidas, visando o atendimento das expectativas da rede logística e a qualidade dos serviços oferecidos. Sugere-se a realização de novas pesquisas tendo como foco a temática apresentada nesta investigação ou, talvez, a inserção de novos enfoques que estejam relacionados ao segmento de alimentos e bebidas. Esperase, ainda, que esta investigação contribua de forma significativa no aprofundamento de novas pesquisas e estudos.

\section{Referências bibliográficas}

ALLEN, J; O'TOOLE, W; MCDONNEL, I; HARIS, R. Organização e gestão de eventos. 3 ed. Rio de Janeiro: Campus, 2008.

BABBIE, E.The Practice of Social Research. California: Wadsworth Publishing Company, 1998.

BALLOU, R.H. Gerenciamento da cadeia de suprimentos: planejamento, organização e logística empresarial. 4. ed. Porto Alegre: Bookman, 2001.

BARBOSA, F.S. O Processo Logístico de Eventos: um estudo de caso da Oktoberfest de Blumenau/SC. Dissertação (Mestrado em Turismo e Hotelaria). Universidade do Vale do Itajaí, Balneário Camboriú, 2010.

BOWERSOX, D.J.; CLOSS, D.J. Logística empresarial: o processo de integração da cadeia de suprimento. São Paulo: Atlas, 2001. 
Barbosa, F.S.; Heize, R.S.S.; Carmo, A.J.R.R.S.

BOWERSOX, D.J; CLOSS, D.J; COOPER, M.B. Gestão logística de cadeia de suprimentos. Porto Alegre: Bookman, 2006.

CHAUMIER, J. Systèmesd'information: marche et technologies. Paris: Entreprise Moderne, 1986.

CHRISTOPHER, M. Logística e gerenciamento da cadeia de suprimentos. São Paulo: Pioneira Thomson Learning, 1997.

CORRÊA, Henrique L.; CAON, M. Gestão de Serviços - Lucratividade por meio de operações e de satisfação dos clientes. São Paulo: Atlas, 2002.

CURY, R. Logística aplicada ao turismo. In: RUSCHMANN, D.; SOLHA, K.T. (Org.).Turismo: uma visão empresarial. São Paulo: Manole, 2004. p. 15-28.

DA SILVA, C.A.V.; MUSETI, M.A. Logística militar e empresarial: uma abordagem reflexiva. Revista de Administração, São Paulo, V. 38, n. 4, p. 343-354, out/nov/dez, 2003. ISSN 0080-2107

DENCKER, A.F.M. Métodos e técnicas de pesquisa em turismo. São Paulo: Futura, 1998.

EISENHARDT, K.M. Building Theories from case study research. Academy of management. v. 14, p. 532-550, 1989.

FEE - Fundação de Economia e Estatística. PIB série histórica 1999-2009. Disponível em: <http://www.fee.tche.br/sitefee/download/pib/municipal/pib-municipal-serie-historica1999-2009.xls>. Acesso em: 10 jan. 2012.

FIGUEIREDO, P.; FLEURY, P.; WANKE. Logística empresarial: a perspectiva brasileira. São Paulo: Atlas, 2003.

FITZSIMMONS, J.A.; FITZSIMMONS, M.J. Administração de Serviços: operações, estratégia e tecnologia da informação. 4를. Ed. Porto Alegre: Bookman, 2005.

GAZERRA, M. A. Ventajas competitivas: una propuesta paso a paso de búsqueda y aplicatión de cadena de valor adaptada a empresas aéreas. Caso Patagônia - Argentina, EAWP, v. 4, n.09, p. 1-36, 2005.

GIL, A. C. Métodos e técnicas de pesquisa social. 4 ed. São Paulo: Atlas, 1994.

IBGE - Instituto Brasileiro de Geografia e Estatística. Dados sobre o município de São

Borja. Disponível em: <http://www.ibge.gov.br/cidadesat/topwindow.htm?1>. Acesso em 08 fev. 2012.

LAUDON, K. C.; LAUDON, J. P. Sistemas de informação com a internet. 4 ed. Rio de Janeiro: LTC, 1999.

MAGNAGO, P. F.; ECHEVESTE, M. E. Caracterização de um modelo mínimo para o PDS por meio de uma revisão sistemática de literatura. Anais do Congresso Brasileiro de Gestão do Desenvolvimento de Produtos 2011. Porto Alegre. Anais CBGDP, 2011.

MARCONI, M.A.; LAKATOS, E.M. Técnicas de pesquisa. 3 ed. São Paulo: Atlas, 2005.

PINTO, M. "Primeiro dos Sete Povos das Missões" a "Terra dos Presidentes": uma análise das políticas e das representações do patrimônio na cidade natal de Getúlio Vargas. Patrimônio e Memória (UNESP), v. 6, p. 261-286, 2010. 
PIRES, S. R. I. Gestão da cadeia de suprimentos: conceitos, estratégias, práticas e casos. São Paulo: Editora Atlas, 2004.

PORTER, M. E. Vantagem Competitiva: criando e sustentando um desempenho superior. 28. ed. Rio de Janeiro: Campus, 1999.

PORTER, M. E. Estratégia competitiva: instrumentos para análise da indústria e da concorrência. Rio de Janeiro: Campus, 1985.

RICHARDSON, R. J. et al. Pesquisa social: métodos e técnicas. São Paulo: Atlas, 1999.

SAMPIERI, R.H et al. Metodologia de la investigación. México: Mcgraw-Hill, 1991.

SILVA, H. H. et al.Planejamento Estratégico de Marketing. 3. ed. Rio de Janeiro: FGV, 2007.

TRIVIÑOS, A. N. S. Introdução à Pesquisa em Ciências Sociais: a pesquisa qualitativa em educação. São Paulo: Atlas, 1987.

WOOD, J. T. Mudança organizacional. 4. ed. São Paulo: Atlas, 2004.

YIN, R. K. Estudo de Caso: planejamento e métodos. Porto Alegre: Bookm

Fabrício Silva Barbosa: Instituto Federal de Educação, Ciência e Tecnologia Farroupilha, São Borja, RS, Brasil.

Email: fbarbosa@sb.iffarroupilha.edu.br

Link para o currículo Lattes: http://lattes.cnpq.br/7960325589026879

Rafael Silvestri Serpa Heinze: Universidade Regional Integrada do Alto Uruguai e das Missões, Erechim, RS Brasil.

Email: rafael.heinze@hotmail.com

Link para o currículo Lattes: http://lattes.cnpq.br/1003013501282237

Annibal José Roris Rodriguez Scavarda do Carmo: Universidade do Vale do Rio dos Sinos, São Leopoldo, RS Brasil.

Email: annibal@esp.puc-rio.br

Link para o currículo Lattes: http://lattes.cnpq.br/6070280268935110

Data de submissão: 30 de junho de 2012

Data de recebimento de correções: 16 de julho de 2013

Data do aceite: 20 de setembro de 2013

Avaliado anonimamente 